\title{
Humoral immune response in Oreochromis niloticus: modified direct agglutination test
}

\author{
Dayanne C. Fernandes - Silas F. Eto $•$ Gustavo S. Claudiano • Paulo F. Marcusso • \\ Flávia C. F. Vieira • Marina T. Shimada • Thiago F. A. Silva • Elaine C. Souza • \\ Rogério Salvador • Julieta R. E. Moraes • Flávio R. Moraes
}

Received: 15 January 2014 / Accepted: 28 May 2014 / Published online: 9 July 2014

(C) Springer-Verlag London 2014

\begin{abstract}
Understanding the functional mechanisms of the humoral and cellular immune responses among teleost broadens the possibilities for intervention and improvement of vaccination methods. The aim of this study was to evaluate the dynamics of the humoral immune response, hematological biochemical changes, and electrophoretic profile of proteins in Oreochromis niloticus, when submitted to antigen stimulation using sheep erythrocytes in a single dose and with booster doses. Seventy $O$. niloticus were distributed in two groups $(n=35)$ : one received a single dose and the other received two doses of antigen. Evaluations were made at the following predetermined times: zero (pre-immune, i.e., before inoculation with the first injection of sheep erythrocytes, negative control) and on 7th, 14th, 21st, and 28th days after the first immunization to evaluate the hemogram, biochemistry, and electrophoresis of proteins and direct hemagglutination. Twenty-eight days after antigen inoculation, it was observed that there had been an increase in the serum antibody titer and fractions gamma globulins after second antigen stimulation. The results suggest that
\end{abstract}

\footnotetext{
D. C. Fernandes · S. F. Eto - G. S. Claudiano - P. F. Marcusso • M. T. Shimada · T. F. A. Silva • J. R. E. Moraes $\cdot$ F. R. Moraes $(\triangle)$ Department of Veterinary Pathology, School of Agrarian and Veterinary Sciences, São Paulo State University (UNESP), Via Prof. Paulo Donato Castellane, km 05, Jaboticabal, SP 14884-900, Brazil e-mail: fruasmoraes@gmail.com

F. C. F. Vieira

Department of Technology, School of Agrarian and Veterinary Sciences, São Paulo State University (UNESP), Via Prof. Paulo Donato Castellane, km 05, Jaboticabal, SP 14884-900, Brazil

E. C. Souza $\cdot$ R. Salvador

Department of Veterinary Pathology, State University of the North of Paraná (Uenp), Luiz Meneghel Campus, Rodovia BR-369 km, Bandeirantes, PR 86360-000, Brazil
}

teleost fish have the capacity to produce antibodies from a single stimulation, and a second antibody production wave after second stimulation.

Keywords Electrophoresis $\cdot$ Immunology $\cdot$ Hemogram $\cdot$ Tilapia $\cdot$ Teleosts

\section{Introduction}

Understanding the functional mechanisms of the humoral and cellular immune responses among teleosts broadens the possibilities for intervention and improvement of vaccination methods. This provides protection, reduction of economic losses, and diminished microbial resistance from use of antibiotics.

Previous assays demonstrated that direct agglutination test using sheep erythrocytes do not cross-react with others tilapia antibodies. But there are various cross reactions against different antigens in this fish species including cross reactions against rabbit erythrocytes (Nunomura 1991; Randelli et al. 2008). Therefore, its use as an antigen would allow us to evaluate Nile tilapia antibodies response without preexisting antibodies interference.

Sheep erythrocytes are complex protein antigens that depend on activation of T lymphocytes (Ocklind 1988). In contrast, bacterial antigens are recognized by receptors with toll-like molecular patterns that are present in phagocytes and some somatic cells, both in mammals and in fishes. They recognize molecular patterns associated with pathogens such as lipopolysaccharides from Gram-negative bacteria and teichoic acid from Gram-positive bacteria (Abbas et al. 2000; Navot et al. 2011).

The direct agglutination used in mammals was modified in this study for the evaluation of dynamics of humoral immune 
response in Oreochromis niloticus without cross reactions and natural antibody, using sheep erythrocytes.

\section{Material and methods}

Fish

Seventy Nile tilapias weighing $80.71 \pm 10.52 \mathrm{~g}$ were used. They were stocked in 10 glass aquariums of $90 \mathrm{~L}(n=7$ each) aquaria provided by water from an artesian well at a flow rate of $1 \mathrm{~L} / \mathrm{min}$, with supplementary aeration. They were fed using commercially available feed $(3 \%$ biomass, $28 \% \mathrm{DP}$, and 4,000 kcal of DE/kg) (ethics committee 011688/12; animal welfare and ISO - the International Organisation for Standardization, 2006). The water quality was kept within the appropriate range of comfort for the fish (dissolved oxygen $=6.1 \pm 1.6 \mathrm{mg} / \mathrm{L}$; temperature $=$ $28.37 \pm 3.8{ }^{\circ} \mathrm{C} ; \mathrm{pH}=6.96 \pm 1.2$; and electrical conductivity $=120.96 \pm 16.3 \mu \mathrm{S} / \mathrm{cm}$ ) (Boyd 1990).

The fish were distributed in a completely randomized manner into two groups $(n=35)$ : one received a single dose and the other received two doses of antigen. Group I (GI) received a single dose of antigen consisting of $2.5 \%$ sterilized sheep erythrocytes in $0.15 \mathrm{M}$ PBS ( $\mathrm{pH} 7.2$ ), at a dose of $250 \mu \mathrm{L}$ per fish by intracelomic route (ic). Group II (GII) received its first injection of sheep erythrocytes in the same way as in GI and then, 14 days later, a second booster injection of the same concentration (ic). Evaluations were made at the following predetermined times: zero (preimmune, i.e., before inoculation with the first injection of sheep erythrocytes, negative control) and on 7th, 14th, 21st, and 28th days after the first immunization.

After acclimatization, the fish were anesthetized in a solution of benzocaine $(1: 20.000)$ diluted in $98^{\circ}$ alcohol $(0.1 \mathrm{~g} / \mathrm{mL})$ (Wedemeyer 1970), as far as the fourth stage of anesthesia (Cosenza et al. 2014). The blood was collected from each fish by puncturing the caudal vein and the procedures for the evaluations at the abovementioned times were performed $(n=7)$.

Agglutination test and inoculums with sheep blood

For the agglutination test, $10-\mathrm{mL}$ samples of sheep blood were collected in graduated $50-\mathrm{mL}$ tubes (Falcon) containing Alsever solution $(\mathrm{v} / \mathrm{v})$ and were centrifuged at $250 \mathrm{~g} / 10 \mathrm{~min}$. The supernatant was discarded, and the erythrocytes were washed with sterilized $0.15 \mathrm{M}$ PBS ( $\mathrm{pH} 7.2$ ) and then centrifuged again at $250 \mathrm{~g} / 5 \mathrm{~min}$. The washing was repeated until the diluent became translucent. Following this, the erythrocyte suspension was diluted to $2.5 \%$ in sterilized $0.15 \mathrm{M}$ PBS ( $\mathrm{pH} 7.2)$. The $2.5 \%$ erythrocyte suspension was aliquoted for each injection and each direct hemagglutination test, and was kept at $4{ }^{\circ} \mathrm{C}$ until the time of use.

Hemogram, biochemistry, and electrophoresis of proteins

The hematocrit percentage was determined using microhematocrit tubes and a hemoconcentration scale (corpuscular volume) (Goldenfarb et al. 1971), and the total plasma protein (TPP) concentration were determined using the biuret method (wavelength $545 \mathrm{~nm}$ ). To obtain the total leukocyte count, a Neubauer chamber was used (Martins et al. 2009), and to obtain the differential count, May-Grünwald-Giemsa-Wright staining was used on blood smears (Tavares-Dias and Moraes 2007).

The total albumin concentration was determined on serum using a colorimetric method, from a commercially available kit (Albumina-K040 ${ }^{\circledR}$ ). The total immunoglobulin (Ig) concentration was calculated, determined by subtraction from the total protein concentration.

The separation of serum protein fractions was performed according to the technique described by Naoum (1990) modified (tapes agarose gel, Tris $\mathrm{pH} 9.5,5 \%$ acetic acid, and amido black dye $0.2 \%$, kept at $100 \mathrm{~V} /$ $20 \mathrm{~min}$ ). The tapes were read using the system SE-250 and obtained the values of the fraction of absolute protein concentration $(\mathrm{g} / \mathrm{dL})$ of each electrophoretic band.

\section{Direct hemagglutination}

The direct agglutination test described by Packham et al. (1998) for Neospora caninum and Lindsay and Dubey (2011) for Sarcocystis neurona was modified in the present study for use with of sheep erythrocyte in tilapia. The serum antibody concentration was determined by means of erythrocyte agglutination in the presence of specific serum antibodies, in order to determine the total antibody titer present in the plasma. The plasma and serum samples were inactivated at $47{ }^{\circ} \mathrm{C} / 30 \mathrm{~min}$ in a water bath. Following this, serial $\log 2$ dilutions of these samples were performed on microtiter plates with a U-shaped bottom. For this, $50 \mu \mathrm{L}$ of PBS was added to each well and then $50 \mu \mathrm{L}$ of inactivated plasma was added to the first well of the plate. The solution was then homogenized, and $50 \mu \mathrm{L}$ was transferred to the next well. This process was repeated as far as the eleventh well, where the same volume of solution was then discarded. This procedure was done for all the plasma samples in the preimmune evaluation and on the 7th, 14th, 21st, and 28th days after immunization.

Following this, an equal volume of $2.5 \%$ sheep erythrocytes was added to each well and the plate was incubated for one hour at $37^{\circ} \mathrm{C}$ and $22 \mathrm{~h}$ at $4{ }^{\circ} \mathrm{C}$. After this period, the plates were observed visually to compare the sedimentation pattern of the control well without plasma (12th well) with the sedimentation patterns of the other wells. The total antibody titer 
was identified as the greatest dilution at which it was possible to observe positive agglutination of erythrocytes. The results were expressed as the $\log _{2}$ of the reciprocals of the serum titers, and the processed data were subjected to statistical analysis.

\section{Statistical analysis}

The results were subjected to analysis of variance and comparison of means using Tukey's test, at the significance level of $5 \%(p<0.05)$ (Snedecor and Cochran 1974). Pearson's correlation was applied between the total antibodies and absolute lymphocytes at the significance level of $5 \%$.

\section{Results}

Blood variables

From the analysis of the hematological values was observed that corpuscular volume maintained the same pattern between the different groups throughout the experimental period (Table 1).

In GI, the leukogram presented significantly higher total leukocyte counts on the 14th and 21st days, comparing to the values observed in the preimmune evaluation, and was observed to have decreased on the 28th day. In GII, the total count on the 28th day was significantly greater than that observed in GI on the 28th day (Table 1).

The absolute lymphocyte count was higher on the 7th day than in the preimmune evaluation, and was observed to have decreased on the 14th day. These differences were statistically significant $(p<0.05$; Table 1$)$. The GII presented the same response dynamics until the 14th day, but presented significantly higher values $(p<0.05)$ on the 21 st and 28th days, in comparison with the values observed in GI (Fig. 1b).

There was a positive correlation between higher absolute lymphocyte counts and the serum antibody titers produced in GII, in which $48 \%$ of the increase in antibody production was attributable to the higher lymphocyte count (Figs. 1 and 2). No positive correlation was observed in GI.

The total immunoglobulin concentration did not present any significant difference $(p>0.05)$ in the individual evaluation between GI and GII. However, comparing the values within GII, the values on the 21 st day were higher $(p<0.05)$ than in GI (Table 1).

The total plasma protein concentration presented a gradual decrease $(p<0.05)$ over the course of time in both groups, but without any statistical difference $(p>0.05)$ between them. There was no difference in albumin between the groups (Table 1).
Subdivision serum protein electrophoresis allowed the observation of four distinct fractions: albumin, $\alpha$-globulin, $\beta$ globulin, and $\gamma$-globulin (Fig. 3b); checking increase $(p<0.05$; Table 1) protein concentration in the gamma fraction of tilapia that has received the second dose with 28th days after antigenic stimulation (Fig. 3a).

\section{Humoral immune variables}

The preimmune evaluations did not present any serum titers against sheep erythrocytes during the experimental period (Table 1). The pattern for the serum antibody curve (GII) presented statistical differences $(p<0.05)$ between the evaluation done before the inoculation and the evaluations done on the 7th, 14th, 21st, and 28th days after immunization. The serum titer was higher $(p<0.05)$ on the 21 st day and decreased $(p<0.05)$ on the 28th day (Table 1). The GII presented the same curve pattern as shown by GI up to the 21 st day (Fig. 1a). Comparison of the two curves between the groups showed higher serum titers in GII $(p<0.05)$ on the 21 st and 28th days, in relation to GI (Fig. 1a). The inoculations of sheep erythrocytes into the tilapias did not interfere with the body weights, which did not present any statistical differences $(b<0.05)$ (data not shown).

\section{Discussion}

The presence of serum antibodies on the 7th, 14th, 21st, and 28th days in the two groups showed primary and secondary humoral immune response patterns that were similar to those found in mammals (Tizard 2011).

A study in which a single dose of Vibrio harveyi was inoculated into Epinephelus bruneus showed a response consisting of progressive increases in the antibody titers on the 7th to 21st days after inoculation (Harikrishnam et al. 2012). This is similar to what we have found among the GI fish, which received a single injection of sheep erythrocytes. On the other hand, the GII fish presented an increase in the titer on the 28th day, which was consequent to receiving the second antigen stimulation.

Yan et al. (2009) evaluated the humoral immune response among Pseudosciaena crocea against Vibrio alginolyticus and demonstrated that the response was greater, 7 and 15 days after the first and only antigenic stimulation. This result confirms the primary response observed on the 7th day in the present trial, which progressed to the secondary response on the 15th day. In the present study, the secondary response was identified and characterized on the 21st day in the GI. This difference can be attributed to factors such as the difference in the evaluation periods, type of antigenic stimulation, 
政

政

龵

$\hat{\varepsilon} \bar{c}$

萬范

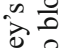

올

$\circ$

罙

莺

政

莺

항

:ृ

蒿

อี

娄

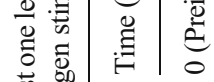

芴

穴得

चु

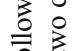

웅

$\stackrel{\overbrace{}}{\approx} \tilde{0}$

范

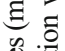

焉

需.

$\sum^{\infty}$

迹

$\stackrel{\infty}{\sim}$

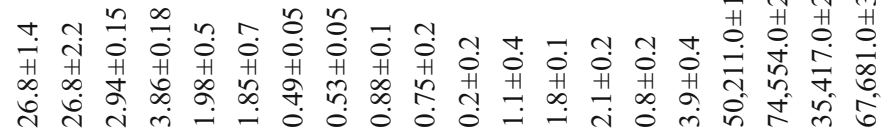

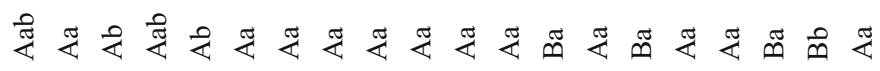

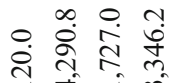

m

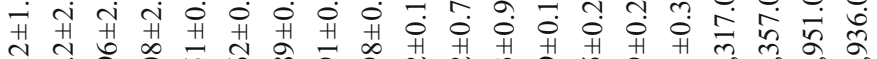

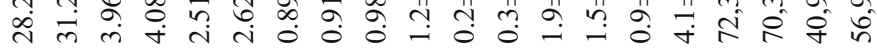

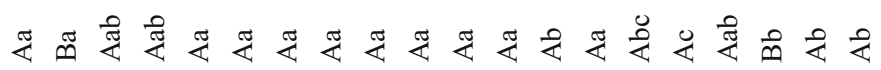

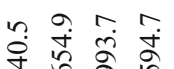

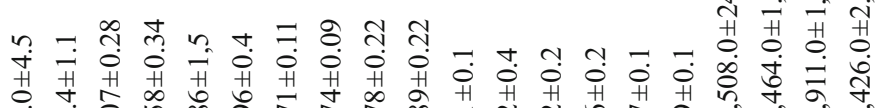

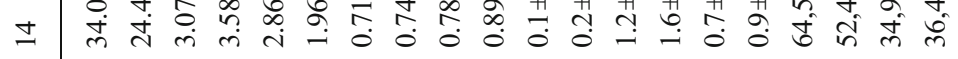

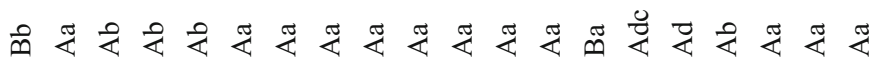

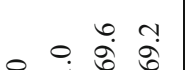

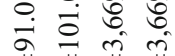

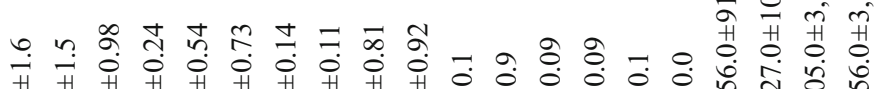

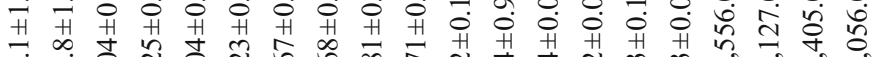

- में

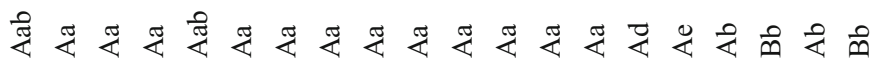

m.

范

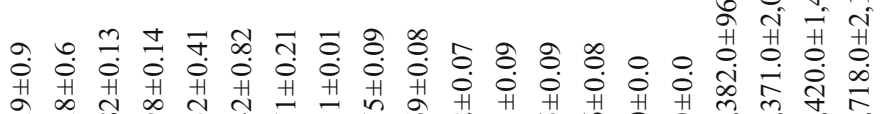

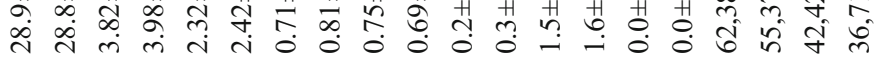

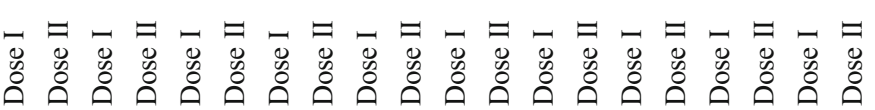

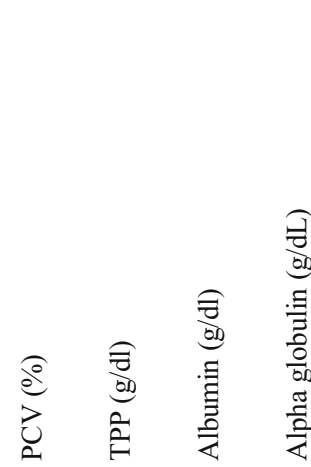

을

矛

홍

苞

爱

矛

要

$\stackrel{0}{ \pm}$

区ี

8

号

हैं

燕

E

¿

$$
\text { 항 }
$$

$\cong$

ปั้

瓷

窇

这

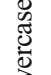




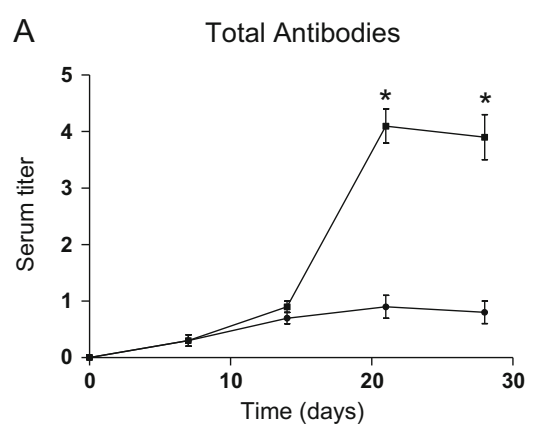

Fig. 1 Kinetics of the humoral response (a) and lymphocytic response (b) $(n=7)$ in tilapias immunized with sheep red blood cells. Each point represents the mean \pm standard error of the mean of the antibody titer and

inoculation site, and species used. Nonetheless, the curve patterns in the two studies were similar.

In mammals, it has been postulated that the second dose of antigen reactivates the $\mathrm{B}$ and $\mathrm{T}$ memory clones that come from the first clonal expansion, with increased antibody production and generation of the second clonal expansion, and with exchange of the suite of class $\operatorname{IgM}$ for $\operatorname{IgG}$ (Abbas et al. 2000). This exchange from IgM to $\operatorname{IgG}$ does not occur in teleosts in the way that is seen in mammals, but associations with low metabolic rate, limitations to genetic mechanisms, absence of histomorphological structures as germinative centers and absence of lymph nodes may interfere with the intensity and dynamics of antibody production in teleosts (Kaatari et al. 2002).

In the present study, the higher antibody titers on the $21 \mathrm{st}$ and 28th days after antigenic stimulation of the GII comparing

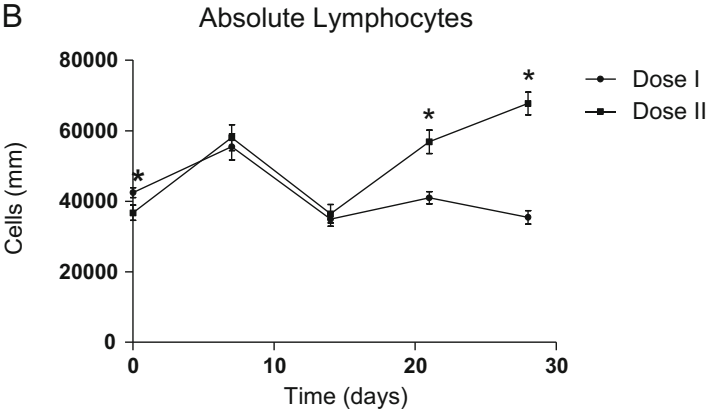

the lymphocyte count observed in the groups immunized once or twice with sheep erythrocytes. *Significant difference according to Tukey's test $(p<0.05)$

to the GI, demonstrates increase in antibody titers and alpha globulin fraction. It is possible that the clonal expansion of $\mathrm{B}$ and $\mathrm{T}$ lymphocytes occurs at other sites that are not morphologically organized in the way seen in mammals (Kaattari et al. 2002).

Data from a study on Carassius auratus (Navot et al. 2011) showed similarities with what was obtained in this study, given that there was an increase in the serum antibody titers after the second dose of vaccine against Aeromonas salmocida, 3 weeks after the first dose. The same study found preformed natural antibodies or cross-reaction antibodies against to the antigen studied, and thus, the titers of these natural antibodies may have interfered with the subsequent antibody production results. No presence of reactive natural antibodies to antigens present in the sheep erythrocyte membrane was detected in the present study. In the used

- Linoar Regestion

- 95: Contidence Irierval

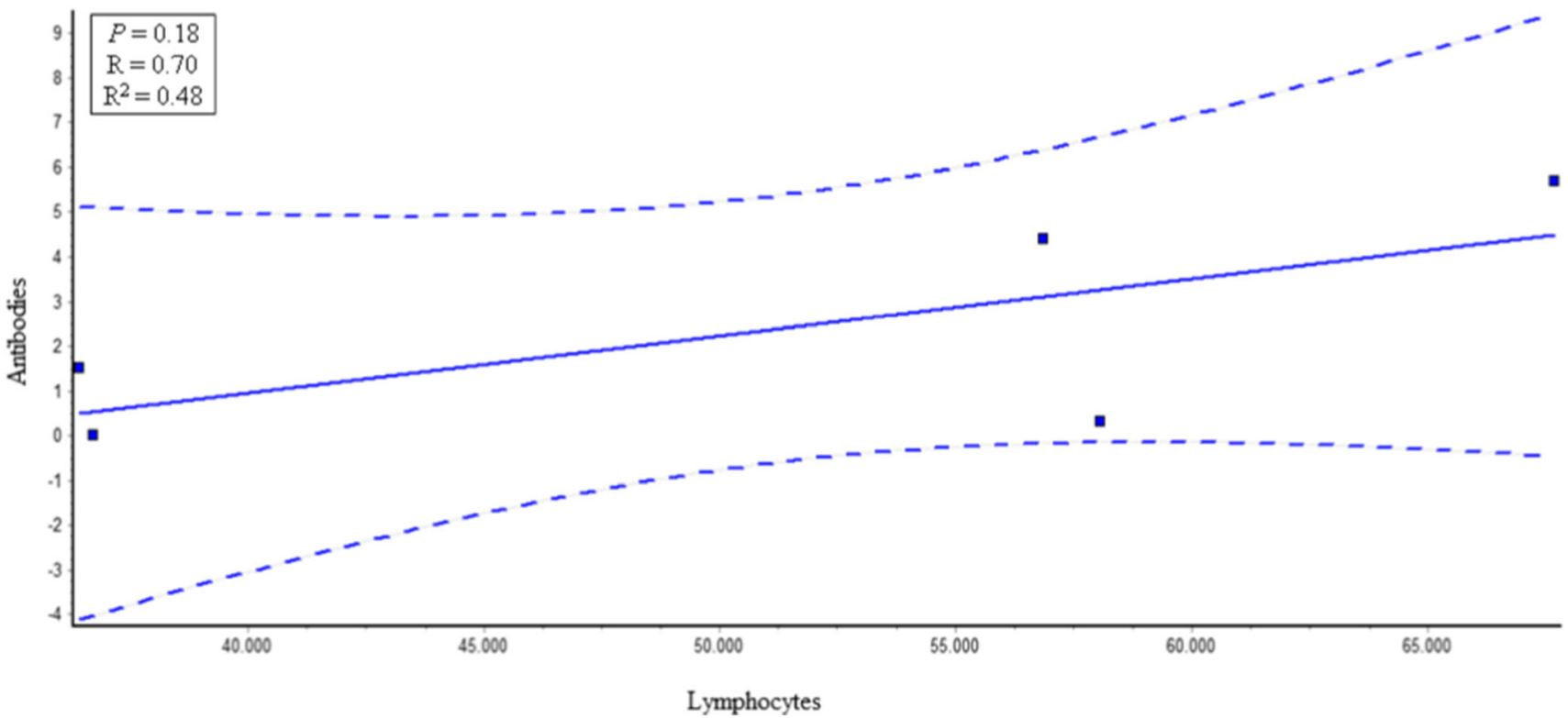

Fig. 2 Positive simple linear correlation, presenting the linear regression trend line, $p$ value $(P)$, correlation coefficient $(R)$, and coefficient of determination $\left(R^{2}\right)$ between the absolute lymphocyte count and the serum antibody titers in tilapias immunized twice with sheep erythrocytes (group GII) 
experimental model, there was no interference from natural antibodies or cross-reactions which could mask the dynamic of humoral immune response, a fact that makes response evaluation safer, and therefore, more accurate.

Sheep erythrocytes are complex protein antigens that depend on activation of T lymphocytes (Randelli et al. 2008). In contrast, bacterial antigens are recognized by receptors with toll-like molecular patterns that are present in phagocytes and some somatic cells, both in mammals and $O$. niloticus (Zhao et al. 2013). They recognize molecular patterns associated with pathogens such as lipopolysaccharides from Gramnegative bacteria and teichoic acid from Gram-positive bacteria (Abbas et al. 2000; Navot et al. 2011) may favor crossreactions and interfere in the dynamics of the humoral and

\section{Days (I Dose)}

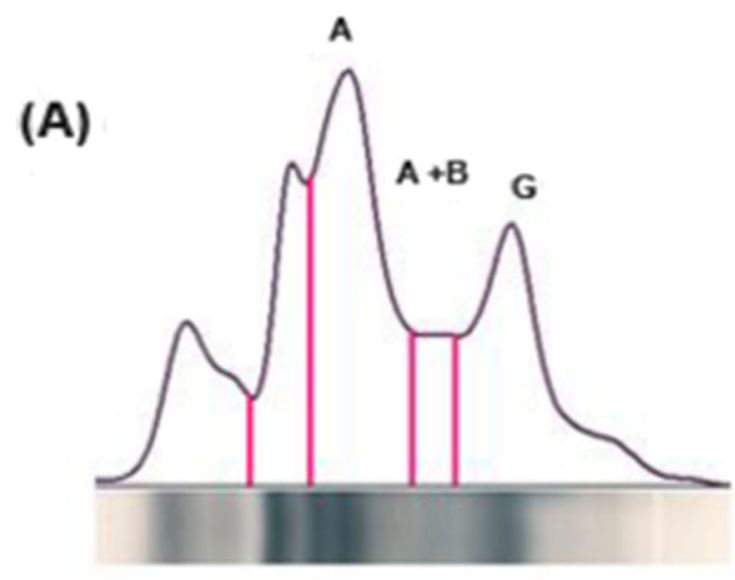

(B)

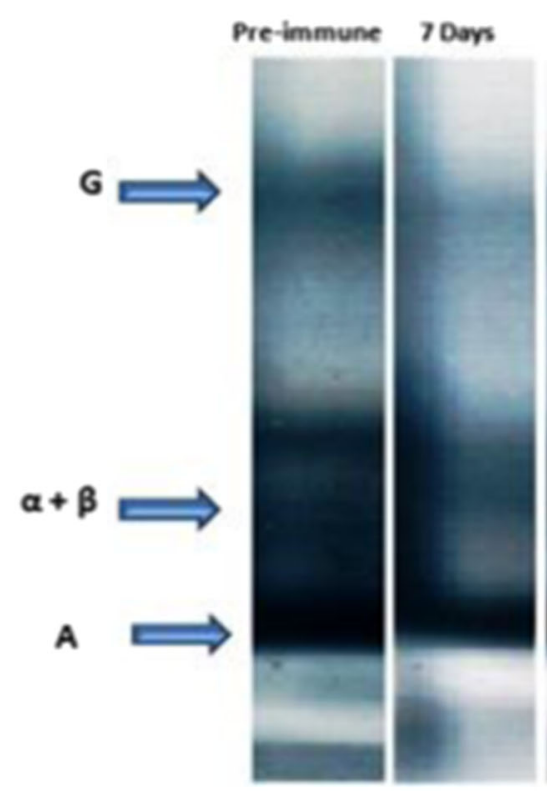

Fig. 3 Electrophoretic profile of serum proteins (a) and agarose gel (b): albumin (A), alpha globulin $(A ; \alpha)$, beta globulin $(B ; \beta)$, and gamma globulin $(G)$ in Nile tilapias subjected to inoculation cellular immune response. This was reflected in the leukocyte dynamics accumulation observed in a study on Piaractus mesopotamicus, using inoculations of different stimuli (Bozzo et al. 2007). In the sheep erythrocytes antigens case, the use of these toll-like molecular patterns did not interfere with the response mechanism as shown in Table 1. The increase in the blood total leukocyte count consequent to the increased absolute lymphocyte count on the 7th day, in both groups after the first stimulation and in GII in relation to GI on the 28th day, suggest that new lymphocytes were recruited from reserves compartments for the blood 7 days after the first stimulation and 7 days after the second stimulation.

The positive correlation between the absolute lymphocyte counts and the serum antibody titers suggest that an increase

\section{Days (II Doses)}
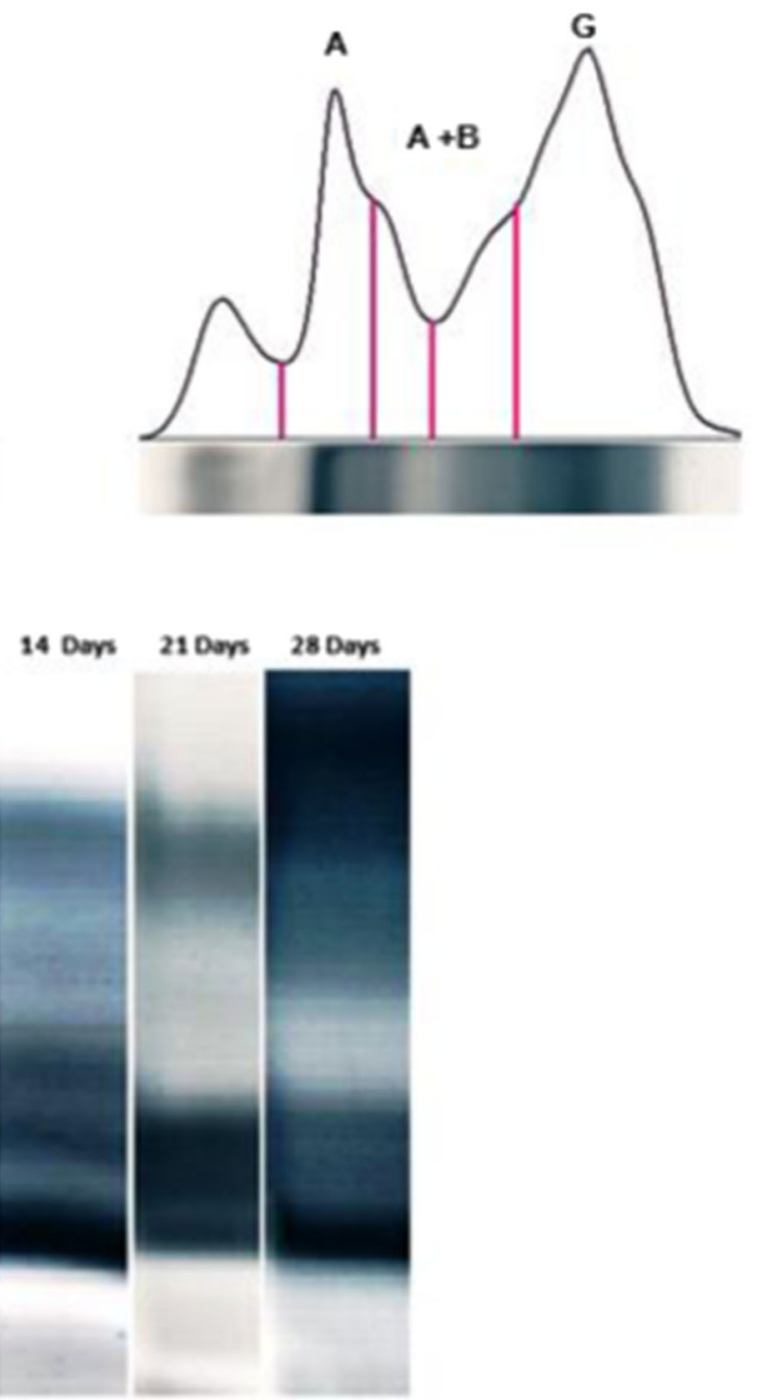

with one or two doses of antigen stimulation with sheep erythrocytes: 7 th, 14th, 21st, and 28th days after immunization 
in the counts of these cells can occur. The fact that there haven't had natural antibodies or cross-reactions against the antigenic constitution of sheep erythrocytes may have favored the identification of such responses. The total immunoglobulin concentration and serum protein electrophoresis reflects the same response pattern as seen in the specific antibody response and lymphocyte counts between the groups, with increased serum concentration on the 21st day and a subsequent decrease on the 28th day, as occurred with the other variables evaluated.

Harikrisman et al. (2012) observed that there was an increase in the serum immunoglobulin concentration 2 weeks after the first antigenic stimulation with the bacterial antigen of $V$. harveyi and 4 weeks after the second immunization. These values were not observed in this study, but the absence of an increase on the 14th day after the second week, as seen by Harikrisman et al. (2012), can be explained by collections that were done at 7-day intervals, rather than 14-day intervals, which could diminish the quantity of these systemic immunoglobulins during the experimental period.

In conclusion, the results suggest that teleost fish have the capacity to produce antibodies from a single stimulation, and a second wave of antibody production after the second stimulation. The use of sheep erythrocytes allowed a more accurate evaluation of the dynamics of humoral immune response, since that it has not cross-reactions or natural antibodies interference.

Acknowledgments The authors would like to acknowledge the Araucaria Foundation (Scientific Initiation Scholarship).

\section{References}

Abbas AK, Lichtman AH, Pober JS (2000) Cellular and molecular immunology, 4th edn. WB Saunders, Philadelphia

Boyd CE (1990) Water quality in ponds for aquaculture. Alabama agricultural experiment station, Auburn University, AL

Bozzo FR, Moraes JRE, Moraes FR, Pereira M, Tavares-Dias M, Onaka EM (2007) Kinetics of cellular component in inflammatory response induce by different Stimuli in the swim bladder of Pacu, Piaractus mesopotamicus Holmberg 1887 (Characidae). J World Aquac Soc 38:302-308. doi:10.1111/j.1749-7345.2007.00100.x

Cosenza GR, Claudiano GS, Marcusso PF, Eto SF, Manrique WG, Loureiro BA, Shimada MT, Salvador R, Moraes JRE, Moraes FR (2014) Influence of glyceryl guaiacolate ether on anesthetics in tilapia compared to benzocaine and eugenol. Rev MVZ Córdoba 19(1):3944-3953, ISSN: 0122-0268

Goldenfarb P, Bowyer F, Hall E (1971) Reproducibility in the hematology laboratory: the microhematrocrit determination. Am J Clin Pathol 56:35-39
Harikrishnam R, Kim JS, Balasundaram C, Heo MS (2012) Vaccination effect of liposomes entrapped whole cell bacterial vaccine on immune response and disease protection in Epinephelus bruneus against Vibrio harveyi. Aquaculture 342:69-74. doi:10.1016/j. aquaculture.2012.01.038

Kaattari SL, Zhang HL, Khor IW, Kaattari IM, Shapiro DA (2002) Affinity maturation in trout: clonal dominance of high affinity antibodies late in the immune response. Dev Comp Immunol 26: 191-200. doi:10.1016/S0145-305X(01)00064-7

Lindsay DS, Dubey JP (2011) Direct agglutination test for the detection of antibodies to Sarcocystis neurona in experimentally infected animals. Vet Parasitol 95:179-186. doi:10.1016/S0304-4017(00) 00389-7

Martins ML, Miyazaki DMY, Tavares-Dias M, Fenerick JRJ, Onaka EM, Bozzo FR, Fujimoto RY, Moraes FR (2009) Characterization of the acute inflammatory response in the hybrid tambacu (Piaractus mesopotamicus male x Colossoma macropomum female) (Osteichthyes). Braz J Biol 69:957-962. doi:10.1590/S151969842009000400026

Naoum PC (1990) Eletroforese - técnicas e diagnóstico. Livraria Santos, São Paulo

Navot N, Michel SS, Avtalion RR (2011) Application of ultrasound in vaccination against goldfish ulcer disease: a pilot study. Vaccine 29: 1382-1389. doi:10.1016/j.vaccine.2010.12.069

Nunomura W (1991) Immune response of the thymus to sheep red blood cells in white spotted char (Salvelinus leucomaenis). Bull Fac Fish Hokkaido Univ 42(3):85-89, http://hdl.handle.net/2115/24079

Ocklind G (1988) Activation of human T lymphocytes through CD3 and CD2 (T11) with anti-CD3-coupled sheep erythrocytes. Scand J Immunol 27(5):609-613. doi:10.1111/j.1365-3083.1988.tb02389.x

Packham AE, Severlow KW, Conrad PA, Loomis EF, Rowe JD, Anderson ML, Marsh AE, Cray C, Barr BC (1998) A modified agglutination test for Neospora caninum: development, optimization, and comparison to the indirect fluorescent-antibody test and enzyme-linked immunosorbent assay. Clin Diagn Lab Immunol 5: 467-473

Randelli E, Buonocore F, Scapigliati G (2008) Cell markers and determinants in fish immunology. Fish Shellfish Immunol 25:326-340. doi:10.1016/j.fsi.2008.03.019

Snedecor GW, Cochran (1974) Statistical methods, 7th edn. Iowa State University, Ames

Tavares-Dias M, Moraes FR (2007) Leukocyte and thrombocyte reference values catfish (Ictalurus punctatus Raf), with an assessment of morphologic, cytochemical, and ultrastructural features. Vet Clin Pathol 36:49-54. doi:10.1111/j.1939-165X. 2007.tb00181.x

Tizard IR (2011). O Fenômeno da Imunidade, In: Ibid. (Ed.), Imunologia Veterinária: uma introdução. $8^{\mathrm{a}}$ ed. Roca, São Paulo; 2002

Wedemeyer G (1970) The role of stress in the disease resistance of fishes. Am Fish Soc 5:30-35

Yan Q, Zhang J, Zou W, Chen Q, Zhuang Z, Wang X (2009) Immune response of Pseudosciaena crocea to the injection of Vibrio alginolyticus. Chin J Oceanol Limnol 27:85-91. doi:10.1007/ s00343-009-0085-0

Zhao F, Li YW, Pana HJ, Shi CB, Luo XC, Li AX, Wua SQ (2013) Expression profiles of toll-like receptors in channel catfish (Ictalurus punctatus) after infection with Ichthyophthirius multifiliis. Shellfish Immunol 35:993-997. doi:10.1016/j.fsi.2013.05.023 